\title{
Producing Salmonella-free pigs: a review focusing on interventions at weaning
}

\author{
A. D. Wales' ${ }^{1}$, A. J. C Cook ${ }^{2}$, R. H. Davies ${ }^{1}$
}

${ }^{1}$ Department of Bacteriology, and ${ }^{2}$ Centre for Risk Analysis and Epidemiology.

Veterinary Laboratories Agency - Weybridge, Woodham Lane, New Haw, Addlestone, Surrey KT15 3NB, UK.

Author for correspondence: Andrew D. Wales

Email: research@andy.wales

Tel: $\quad$ +442920842402/ +447743506273

Running head: Producing Salmonella-free weaners

Copyright BMJ Journals.

DOI: $10.1136 / v r . d 1125$

Published online at: http://veterinaryrecord.bmj.com/content/168/10/267.abstract 


\section{Impacts}

- Salmonella carriage by young pigs is common and typically asymptomatic in modern production systems, although the frequency of infection before weaning is currently uncertain.

- Interventions aimed at reducing Salmonella infections in young pigs have variable success rates and typically suppress rather than eliminate the problem.

- Segregated weaning utilises a change in the piglet environment at a time when maternallyderived immunity to Salmonella should be high, and shows promise for the elimination of Salmonella early in the production cycle.

\section{Summary}

Salmonella infection in pig production is typically endemic and largely asymptomatic, and is a cause of substantial concern among food safety bodies, prompting voluntary and legislative responses aimed at monitoring and reducing the number of Salmonella-infected animals entering the human food chain. Elimination of the problem at an early stage of production is highly desirable, and to this end the present review examines published evidence on the carriage of Salmonella by piglets before and after weaning, plus evidence on the dynamics of Salmonella infection in the weaner and grower stages of pig production, the effects of maternal immunity, and risk factors for Salmonella excretion after weaning. Various interventions to reduce or eliminate Salmonella infection in young pigs have been tried, such as vaccination, competitive exclusion, feed and water treatments, antibiotic administration, disinfection of animals, and segregated weaning to clean accommodation. The evidence on the effectiveness of these is considered, and the last is examined in some detail as it appears presently to offer the best chance of eliminating Salmonella from growing stock.

Keywords: Salmonella, swine, weaning, vaccination, competitive exclusion 


\section{Introduction}

Evidence from surveillance in Europe and elsewhere (Davies and others 2004, ANON 2006b, EFSA 2008), and of clinical experience (Taylor 1989) is that Salmonella infections of pigs with currently-prevalent serotypes are often widespread but typically asymptomatic. For example, a systematic European Union survey of ileo-caecal lymph nodes at slaughter revealed national prevalences of between zero and $29 \%$ of pigs positive and a communitywide prevalence of $10.3 \%$, with 12 countries (including the UK) having prevalences above $10 \%$ and only six countries (notably including the Scandinavian peninsula) below five percent (EFSA 2008). Pig Salmonella infections involve limited invasion of tissues, including pharyngeal tonsils and mesenteric lymph nodes (MLN) (Reed and others 1985, 1986, Wood and others 1989). Recent assessments of human salmonellosis have suggested that around $22 \%$ of cases in the Netherlands and $14 \%$ of cases in Denmark may be attributed to pork or pork products (ANON 2006a). Programmes in several countries, including the UK and Denmark, are aimed at reducing the Salmonella risk from pigs entering slaughterhouses by means of biosecurity and hygiene action plans informed by serological monitoring, with financial and marketing penalties for evidence of persistently high seroprevalence. However, it is plausible to consider attempting to completely eliminate Salmonella infections from young pigs through to slaughter weight by various interventions before or at weaning. A body of experimental and small-scale field work suggests that this may be a viable strategy for the pig industry, but it is difficult to design reliable strategies for this highly-desirable goal with the fragmentary evidence that exists. The present review attempts to provide an overview of progress in this field.

\section{Prevalence of Salmonella in nursing pigs}

There are limited data on the prevalence of Salmonella infection or excretion in pre-weaned piglets. Individual sampling can be the only reliable guide to piglet infection, as environmental samples will include contamination by the sow. Between $2 \%$ and $9 \%$ of sucking piglets excreted Salmonella Typhimurium (ST) in an endemically infected German breeding herd (Roesler and others 2005). In a French commercial herd, 1.2\% of sucking piglets yielded Salmonella, again ST, in the context of about a third of farrowing or nursing sows excreting a variety of serovars (Belœil and others 2003). In 12 endemically-infected herds in the USA, cross-sectional and cohort studies showed excretion by $3 \%$ and $0.4 \%$ of sucking piglets, respectively. Maximal values for individual farms were $3.5 \%$ and $5 \%$ respectively (Barber and others 2002). Investigation of five cohorts in two multi-site integrations in the USA showed within-cohort prevalences of Salmonella excretion of between $0.5 \%$ and $7 \%$ of piglets (Funk and others 2001). Similar ranges of prevalence were seen among nursery pigs and nursing sows in the same study, except for one nursery where $46 \%$ of pigs were excreting. A higher proportion of Salmonella-positive sucking piglets (13.3\% overall, $22 \%$ on one farm) was reported from a Nigerian survey of five farms (Amaechi and Ezeronye 2006).

It does not appear that farrowing and lactation are periods associated with increased maternal shedding of Salmonella (Nollet and others 2005a) and there is evidence, from a limited number of units, that the proportion of animals in a cohort excreting Salmonella may be lower among lactating sows (zero to 9.1\%) than among pregnant sows (17.4 to 41.3\%)on the same unit (Funk and others 2001, Korsak and others 2003). However, it is not uncommon to observe the excretion of Salmonella by farrowing and lactating sows (Fedorka-Cray and others 1997, Funk and others 2001, Barber and others 2002, Belœil and others 2003, Nollet 
and others 2005b), and substantial contamination of the farrowing environment by Salmonella may also be found (Funk and others 2001, Wales and others 2009). Overall, breeding gilts and sows have been found to have a higher frequency of Salmonella excretion than pigs in the nursery, grower and fattener phases (Wilkins and others 2010) although peak excretion appears to occur after weaning (Nollet and others 2005a). There has been little published work specifically examining risk factors for Salmonella excretion by sows, although health status and pelleted feed appear to be positive risk factors (Kranker and others 2001).

\section{Sources of infection for weaners}

A proportion of Salmonella strains acquired around birth and nursing do appear to persist in older pigs (Berends and others 1996). One author (Dahl 2008) asserts that certain serovars in sow herds ( $S$. Typhimurium, and probably $S$. Derby) are more likely to be transmitted through to the finisher stage than others, which may contribute towards variability in the findings of investigations seeking to examine this route of transmission. $S$. Derby is an example of a broad host range serovar that nonetheless does appear to be stable and persistent in farmed pigs in many parts of the world (Boyen and others 2008). One strand of evidence for the persistence of pre-weaning Salmonella strains in older pigs is the observation that some piglets excrete the same Salmonella strains before and after weaning. This was reported with $S$. Typhimurium in a small proportion of piglets in one field study (Belœil and others 2003). Further evidence, showing that these carried-over strains can establish in post-weaning groups, comprises correlations between Salmonella strains found in the breeding herd or nursing accommodation and in weaned pigs. Salmonellas detected in the later stages of rearing in three herds included (but were not restricted to) some serovars also found in the maternal herd (Nollet and others 2003b). Furthermore, clonal strains of $S$. Typhimurium DT108, $S$. Anatum and $S$. Derby were found at all stages of an integrated multi-site production unit (Letellier and others 1999).

The presence of common Salmonella strains at different stages of production does not provide evidence of a mechanism for the dissemination of strains. It may be that Salmonella could be carried into weaner accommodation directly, via the intestinal or respiratory tracts of piglets or on their body surfaces. A topical iodophor disinfectant applied at weaning to piglets from Salmonella-excreting sows reduced the risk of Salmonella isolation from piglets 10 days later (Patchanee and others 2005), which suggests that the last route may in some circumstances be significant. However, indirect spread may also occur, particularly on singlesite farrow-to-finish farms (Nollet and others 2005b). The possibility that indirect routes may be significant is supported by two field analyses, wherein a breeding sow batch being Salmonella-positive was a risk factor for weaner pens being similarly positive (Kjærsgaard and others 2001), but individual sows excreting Salmonella did not constitute a risk factor for their own piglets excreting Salmonella after weaning (Nollet and others 2003b). Thus, direct carryover from sow to weaner appears to be a low frequency event, although may be more common in gilt litters where maternal immunity can be weaker. Furthermore it may be that in the common situation where more than one Salmonella serovar is present, indirect infection of weaners with a serovar to which they have little or no passive immunity may be an alternative route.

There is little doubt that cleaning and disinfection (C\&D) of post-weaning accommodation (and more generally on pig farms) is often insufficient to remove pre-existing Salmonella contamination (Berends and others 1996, Funk and others 2001, Wales and others 2009), so endemic serovars in weaner and grower accommodation probably constitute one of the major sources of Salmonella in the post-weaning phase, negating the benefits of Salmonellanegative incoming stock (Dahl 2008). Furthermore, young stock is likely to be 
immunologically naïve to Salmonella serovars that are endemic in post-weaning accommodation, thereby promoting the establishment and propagation of infections within groups (Berends and others 1996, Letellier and others 1999, Funk and others 2001).

Ingredients for animal feedstuffs are commonly contaminated with salmonellas (Hacking and others 1978, Jones and Richardson 2004, ANON 2006b, European Food Safety Authority 2006). Contamination, by ingredient strains or de novo by endemic feed mill Salmonella strains, is commonly found in the resulting compounded feeds, including those that have undergone heat treatment (Hacking and others 1978, Veldman and others 1995). Recent data from EU countries shows national rates for compounded pig feed samples of up to $1.7 \%$ Salmonella-positive (European Food Safety Authority 2006). However, this is likely to be an underestimate of the scale of contamination owing to the difficulty of representative sampling of large consignments of feed (Jones and Richardson 2004). Some studies have shown strong links between the Salmonella contamination of feedstuffs or feed mills and infections of groups of pigs (Newell and others 1959, Österberg and others 2006). However, whilst serovar patterns in animals can suggest feedmill sources, most strains found in feedstuffs do not readily become established on farms in areas where other sources of Salmonella are more prevalent (Shapcott 1985, Veldman and others 1995). Whilst endemic serovars are likely to be the principal source of Salmonella infections amongst weaners on pig premises, contaminated or recontaminated feed is considered a significant risk factor and may account for up to 15$30 \%$ of Salmonella infections in the finishing period in some situations \{Berends, 1996 $\# 800$ \}. In areas with a low prevalence of Salmonella in livestock, such as certain Nordic countries, feed is the usual means of introduction of Salmonella into pig farms (Häggblom 2009).

Once Salmonella has become established in the environment, or has infected some individuals in a weaned group, experimentally-established routes of transmission to other animals include aerosol, nose to nose contact (Oliveira and others 2006, Oliveira and others 2007 ) and, in numerous dosing experiments, oral ingestion. Nose-to-nose contact was a significant risk factor for Salmonella excretion in one field study (Wilkins and others 2009). Indirect transmission via environmental faeces was demonstrated to be the likely route in one study where two groups of cross-infected pigs had no direct contact with each other (FedorkaCray and others 1994).

\section{Dynamics of infection in the weaner-grower period}

\section{Experimental inoculation studies}

An experiment using the virulent, host-adapted Salmonella Choleraesuis (Anderson and others 1998) showed that infection of piglets immediately after early weaning at two weeks of age by orally-inoculated seeder piglets was slow and required a high inoculum (nearly $10^{9} \mathrm{cfu}$ ) among the seeders. However, infection of older piglets (seven weeks) by the same serovar was more readily and rapidly achieved using seeder individuals inoculated intranasally with around $10^{8} \mathrm{cfu}$ (Gray and others 1996). Secondarily-infected piglets in this study did not excrete Salmonella after eight weeks post-exposure, whereas a small proportion of the directly inoculated piglets continued to excrete beyond this time. Many of the piglets in both groups were Salmonella-negative at post-mortem examination between nine and 12 weeks. In the oral inoculation study (Anderson and others 1998), the concentration of $S$. Choleraesuis in the caecum of orally-inoculated piglets at seven days post-inoculation was around $10^{6}$-fold lower than the original inoculum. However, in the nasal inoculum study (Gray and others 1996) the caecal concentration at the same time point and in older piglets was only around $10^{4}$-fold lower than the inoculum suggesting that, for this serovar, nasal 
exposure offered more opportunity for bacterial colonisation and multiplication than did oral administration.

In comparison to $S$. Choleraesuis, the virulent non-host-adapted serovar $S$. Typhimurium appeared to be more persistent in seven to eight week old piglets, dosed orally with $10^{10} \mathrm{cfu}$ (Wood and others 1989). Excretion was observed for at least 22 weeks, but with increasing individual variation after eight weeks post-inoculation. Post-mortem examinations showed persistent localisation in the caecum, ileocolic lymph nodes and tonsils during the 28 weeks of the study. Faecal-oral cycling of infection was considered likely. Similar internal persistence was observed with the same strain at a similar oral dose (Wood and Rose 1992). In the latter study, counts of ST in the caecum a week after oral inoculation were around ten times higher than the caecal counts of $S$. Choleraesuis at the same time point in the oral inoculation study by Anderson and others (1998). To some extent this may reflect a higher initial dose of ST than $S$. Choleraesuis, but there is also evidence that the latter serovar, being strongly host-adapted, more readily colonises extra-intestinal sites and undergoes less intestinal multiplication and excretion than serovars such as ST that are more restricted to the intestinal tract (Williams and others 1981, Paulin and others 2007).

Another study using eight-week-old pigs and a $10^{10} \mathrm{cfu}$ oral inoculum of a different $S$. Typhimurium strain showed uniform excretion only up to three weeks post-inoculation, with more variable isolation in some groups after that (Fedorka-Cray and others 1994). In the same study, piglets were also secondarily exposed to the inoculum strain via mingling with the inoculated piglets. Interestingly, these uninoculated piglets were rarely found to be excreting Salmonella but showed a high rate of isolation of the test strain at post-mortem examination of ileocolic lymph nodes and in the caecum and ileum. A similar drop-off in the excretion of $S$. Typhimurium was seen following the inoculation of growers around $20 \mathrm{~kg}$ weight with $10^{8} \mathrm{cfu}$ (Nielsen and others 1995). A small proportion of animals showed mild and transient clinical signs post-inoculation, and $60 \%$ excreted at two weeks post-inoculation but only $20 \%$ at four weeks. Nonetheless, a small proportion of pigs yielded the inoculated strain from intestine or tissue samples at post-mortem examination nine to 15 weeks after they were last observed to have excreted it.

Experimental doses of around $10^{8}$ to $10^{9} \mathrm{cfu}$ of serovar Choleraesuis and $10^{10} \mathrm{cfu}$ of Typhimurium in the above studies induced clinical signs including depression, fever and diarrhoea. A $S$. Newport strain of bovine and human provenance was inoculated $\left(10^{10} \mathrm{cfu}\right.$ orally) into seven-week old pigs (Wood and others 1991). It yielded similar patterns of excretion and internal persistence to a porcine $S$. Typhimurium strain reported by Wood and others $(1989,1992)$, although clinical signs associated with the Newport serovar were much milder. The latent carrier state, in which pig faeces may test negative for Salmonella but which involves reactivation of excretion following stress or intercurrent disease (Berends and others 1996, Larsen and others 2003), was observed with serovars Typhimurium and Newport in the above studies. It is considered to be important in the epidemiology of infection.

\section{Field and intervention studies}

Berends and others (1996) asserted that the prevalence of detectably-excreting individuals falls sharply over the first few weeks post-exposure in the rearing and growing phase and becomes intermittent. However, there appears to be great variation in the patterns observed between herds and between studies, even taking into account the differing sample types and methodologies of the various relevant investigations.

A longitudinal study of eight UK breeding farms with established or suspected endemic $S$. Typhimurium infections (Wales and others 2009) used pooled faeces to establish the proportion of Salmonella-positive pens at each visit, which varied from zero to $85 \%$ of weaner pens, and from zero to $81 \%$ of farrowing crates. In five Italian farrow-to-finish herds 
with previous Salmonella-positive samples (Merialdi and others 2008) pooled faeces from pens were infrequently positive (up to 2 of 5 pools positive on any occasion but only 9 of 130 pools positive overall) throughout the weaning-finishing period of one cohort on each farm. At slaughter, 12 of 150 ileocaecal lymph nodes yielded Salmonella.

In three Danish farrow-to-finish herds with $S$. Typhimurium present, a cohort study using culture of individual faeces samples did not show any Salmonella excretion at weaning (Kranker and others 2003a). A peak Salmonella prevalence (around 30\%) was seen at two months of age; subsequently overall prevalences of around $10 \%$ and zero were seen at five and six months respectively, although there was wide variation between cohorts and herds. Fifty-three percent of pigs were culture-positive at any stage, but only $3.7 \%$ were culture positive at more than one monthly sampling.

Cohorts of between 96 and 120 piglets, from 32 to 40 sows, were monitored in three Belgian farrow-to-finish units with endemic Salmonella in the breeding herd (Nollet and others 2003a, 2005b). The onset of detectable Salmonella excretion was during the postweaning nursery period in one herd and at around 11 weeks of age in another herd.

Salmonella was never detected in piglets from the third herd. In the first two herds, increased excretion was seen after moving piglets to grower accommodation.

In an intervention field study, untreated groups of piglets showed a low frequency of excretion of $S$. Typhimurium (zero to $6.8 \%$ prevalence) from birth to around 18 weeks of age, when a significant increase to $25.8 \%$ was seen (Roesler and others 2005). A similar pattern was seen in a group treated with a fluoroquinolone antibiotic before weaning.

\section{Serological profiles and correlations with excretion}

Serological responses following experimental oral inoculation with Salmonella appear to vary substantially between individuals. One study involved growers $(20-25 \mathrm{~kg})$ inoculated with $S$. Typhimurium and examined serologically with an anti-lipopolysaccharide ELISA prepared using the same serovar (Nielsen and others 1995). Seroconversion (set at $3.5 \%$ calibrated optical density after reference to negative control sera) was seen in the first animals at seven days post-inoculation, with peak seroprevalence at four to five weeks post-inoculation, declining thereafter. A more conservative $10 \%$ optical density (OD) cut-off, suitable for herd surveys, gave peak seroprevalence at around $80 \%$ of animals, declining to $30 \%$ by 15 weeks post-inoculation, with five of 37 animals excreting Salmonella but not seroconverting at any stage. Individual serological profiles varied substantially in onset and peak OD. Another study using oral inoculation of younger pigs with $S$. Typhimurium and tube agglutination 'O' antigen tests showed a far more rapid onset and decline of serological responses, peaking at one week post-inoculation and subsiding to pre-inoculation levels five weeks later, despite a high frequency of continuing excretion (Wood and others 1989). It is possible that the difference between serological profiles in these studies may be largely technical, with the serological assays preferentially detecting different immunoglobulin subsets.

Roesler and others (2005) found that the temporal pattern of titres correlated well with excretion of $S$. Typhimurium in piglets and growers in a field intervention study, using commercial IgG and IgA-specific ELISA assays. However, individual responses did vary widely in both immunoglobulin subclasses. In another field study, seroprevalence by a mixed ELISA in weaners in three farrow-to-finish herds was seen to peak at around four months of age, two months after the peak of $S$. Typhimurium excretion (Kranker and others 2003a). When sampled monthly from 2 months of age with a $20 \%$ OD cut-off for seroconversion, only $62 \%$ of pigs were sero-positive more than once. In another field study of endemicallyinfected farrow-to-finish herds (Nollet and others 2005b,) serological titres were determined using a mixed Salmonella ELISA. Titres declined from weaning to between eight and 11 
weeks of age, depending on farm, then rose significantly until between 16 and 24 weeks of age. On two farms, rising titres correlated with the onset of Salmonella excretion, whereas on the third no excretion was detected, but Salmonella was isolated from tissues at slaughter. Serology can therefore identify occult Salmonella infection in herds where tissues may subsequently prove to be contaminated at the abattoir, however its value in predicting which individuals may have Salmonella-positive tissues at slaughter appears to be negligible (Belœil and others 2003).

\section{Maternal/colostral immunity profiles}

There is good evidence for a maternal protective effect in respect of Salmonella infection of piglets, which is likely to be mediated via colostral passive immunity. Maternal seropositivity to $S$. Typhimurium, following naturally-acquired infection, proved protective for excretion of this serotype among piglets in the post-weaned nursery stage (Kranker and others 2003b) . Using a mixed ELISA, sows seropositive to undefined Salmonella serovars were also found to be protective for Salmonella excretion in the nursery period (Nollet and others 2003b). Furthermore, the same study showed that Salmonella excretion by sows in the farrowing or lactating period was not associated with an increased risk for Salmonella excretion in their piglets during the nursery stage. Maternal seroconversion induced by vaccination, rather than by natural infection, appears to have a similar protective effect on Salmonella excretion by weaners (Roesler and others 2006), as discussed below in the section on vaccination studies. The relative efficacies of natural infection versus vaccination in this respect are difficult to judge on present evidence, although it might be expected that protection from vaccination may be limited by differences between vaccine and field challenge strains, whilst protection via natural infection would be somewhat unpredictable in practice.

The duration of maternal protection may be estimated by piglet Salmonella immunoglobulin profiles. In one endemically infected herd, a mixed Salmonella ELISA showed piglets to be uniformly seropositive at one week of age and uniformly seronegative at 10 weeks of age (Proux and others 2000). In another herd in the same study, piglets from a strongly-seropositive sow initially showed high titres that declined over the 11 weeks of the study, whereas piglets of moderately seropositive sows had titres that were low by three weeks of age, and increased from eight weeks, probably owing to the development of active immunity. In 256 piglets from a single herd, mixed ELISA Salmonella titres proved to be minimal at around eight to nine weeks of age (Belœil and others 2003), with increasing sow parity and decreasing colostrum immunoglobulin levels being significantly associated with more rapid reductions in titres. Among five farrow-to-finish herds, a mixed ELISA showed that average titres and seroprevalence dropped between 30 and 60 days of age (the seroprevalence to zero in most herds) but rose again by 90 days (Merialdi and others 2008). Similarly, seroprevalence was minimal in piglets of three herds between four and eight to eleven weeks of age (Nollet and others 2003a). A S. Typhimurium-specific ELISA showed minimal IgG titres in piglets at between 40 and 60 days of age from uniformly seropositive sows, many of which were excreting $S$. Typhimurium (Roesler and others 2005). IgA titres showed a similar pattern, although they rose more rapidly than $\mathrm{IgG}$ after 60 days. Individual variation in titres of both immunoglobulin subclasses was minimal at 60 days. In a segregated early weaning trial, without any Salmonella immune stimulation after weaning, 56 earlyweaned piglets from a herd with endemic $S$. Choleraesuis infection were all seronegative when sampled at 83 days of age (Nietfeld and others 1998). 


\section{Modelling study}

Soumpasis and Butler (2009) reported a modelling approach to infections with Salmonella of pig groups after weaning. An assumption was made that, with a high environmental Salmonella load, a 'high propagation' scenario would be triggered, with high infectious loading of animals and high-level excretion. The probabilistic model used predicts that extinction of infection within a group by the time of slaughter will be most likely if there is either a very low initial prevalence of excretion, with no infection cycle initiated, or a very high initial prevalence, causing rapid spread and uniform immunity at a relatively early stage of fattening. The size of the animal group had an inverse relation to the chance of extinction of infection. Factors such as pre-existing environmental contamination and long-term carriers with intermittent excretion were not included in the model.

\section{Summary and discussion of infection dynamics}

Field dynamics of Salmonella infections probably depend on the virulence and persistence characteristics of serovars or strains present and their sources. For example, novel salmonellas from heavy contamination of a weaner or grower environment may spread rapidly and then decline in the face of immunity, whereas serovars carried over from farrowing accommodation by a few individuals may circulate at a low level amongst a group with some pre-existing immunity to them. Thus, individual farm characteristics including management, feeding systems, biosecurity and hygiene procedures and standards are of significant importance for the field dynamics of a Salmonella infection. Experimental inoculation studies report widely differing durations of excretion among groups of pigs, leading to the suspicion that there are significant factors in individual situations that are at present unclear; these may include Salmonella serovar or strain characteristics, environmental opportunities for recycling of infection and pig genetics. Virulence in pigs does not appear to be a prerequisite for persistence, and neither is high-level exposure needed for internal invasion of intestinal and associated lymphoid tissues.

In broad terms, serological findings reflect those of bacteriological investigations of infection dynamics in the post-weaning period, but individuals vary substantially in the timing and intensity of humoral responses. Sow serological profiles may assist in the prediction of the effectiveness of colostral protection of piglets from Salmonella infection. Most studies indicate that passive immunity has declined to minimal levels by around two months of age. However, it remains unclear at what age piglet susceptibility to Salmonella colonisation starts to rise as a consequence of declining passive immunity. There may be other factors, such as the level and nature of milk immunoglobulins (discussed in the vaccination section) or copraantibodies (intestinal $\operatorname{Ig} \mathrm{A}$ ) in sow faeces, which are significant in this respect. These are important considerations for the timing of segregated weaning. Finally, the presence of colostral immunity plus milk immunoglobulins means that it is unclear whether excretion of Salmonella before weaning indicates colonisation of piglets or merely an oral-faecal transit of environmental contamination that ceases rapidly when the piglet is removed from the source of that contamination. These considerations also make it important to establish the rates and sites of Salmonella carriage in piglets at weaning, and large scale post mortem studies are required to elucidate this.

\section{Risk factors associated with excretion of Salmonella in the post-weaning phase}

The use of finely-ground pelleted feed (versus coarse meal) for sows and weaners is reportedly a risk factor for Salmonella in weaner faeces, although the risk is considered to be 
an effect of the feed form on the susceptibility of the alimentary tract to colonisation and replication of Salmonella, rather than the feed being a direct source (Dahl 2008). The effect of feed form on Salmonella infection is more pronounced in later rearing and finishing stages when less digestible least-cost rations are fed. Some studies of pelleted versus meal feed have found no effect of the feed form on Salmonella prevalence in weaner pens (Jørgensen and others 2001, Kjærsgaard and others 2001).

Nose-to-nose contact between pens was a risk factor for pen samples yielding Salmonella among nursery pigs (Wilkins and others 2009). Social stress, induced experimentally by repeatedly swapping individuals between groups, was associated with increased $S$. Typhimurium and coliform excretion in early weaned piglets exposed to the pathogen by seeder animals (Callaway and others 2006). By comparison, temperature, weaning and social stressors were all associated with increased excretion of an enterotoxigenic Escherichia coli strain in three to four-week-old piglets, but assays of humoral and cell-mediated immune function were not significantly affected (Jones and others 2001). A non-immune mechanism for the enhanced excretion of the pathogen was postulated.

In older animals, detection rates of Salmonella from faeces culture can rise substantially following transport to slaughter or new premises (Berends and others 1996, Davies and others 2000, Larsen and others 2003), which may be attributed either to new exposure from the group or re-activation of latent infection due to stress, or both. The transport and mixing of pigs at all ages is a feature of many production systems, and it is to be expected that under such stressors a similar rise in Salmonella excretion would be seen among younger animals also.

The protective effects of sow Salmonella excretion or seropositivity upon Salmonella excretion by nursery pigs has been detailed above. Formal risk analyses of infection carryover from Salmonella-excreting nursing piglets to weaner groups have not been reported.

\section{Intervention studies}

\section{Vaccination}

Many studies on Salmonella vaccination of pigs have been published, the majority of them involving animals vaccinated after weaning, with most reporting beneficial effects but falling short of complete protection (Tunkl and others 1978, Friendship and others 2009). Recent progress in the field has focussed upon modified live vaccine strains, with attendant benefits including enteral or respiratory administration routes, single-dose protocols and theoretically enhanced stimulation of mucosal and cell-mediated immunity (Wray 2001). For example, studies with $S$. Typhimurium in calves indicated that the oral inoculation of attenuated live (aroA-mutant) bacteria, when compared with the injection of killed preparations, provided significantly superior cell-mediated responses and better subsequent clinical protection in the face of virulent $S$. Typhimurium challenge (Lindberg and Robertsson 1983, Robertsson and others 1983). The use in growing pigs of an aroA mutant of $S$. Typhimurium as a parenteral (plus or minus oral) vaccine was reported to reduce shedding times following challenge with a virulent Typhimurium strain (Lumsden and others 1991, Lumsden and Wilkie 1992).

Roesler and others (2004) administered a modified live $S$. Typhimurium vaccine strain with genetic lesions affecting metabolic and outer membrane functions to four-week-old weaners. This induced substantial protection from clinical effects and excretion of a challenge $S$. Typhimurium dose three weeks later. However, the piglet intestinal immune system does not appear to be structurally and functionally fully mature until around seven weeks of age, probably because it has to achieve an ability to discriminate between harmless and pathogen antigens, much more so than immune mechanisms operating away from mucosal surfaces. 
Present evidence (Vega-López and others 1995, Stokes and others 2004) indicates that in the early weeks of life, passive immunity provided by colostrum and milk compensates to some extent for the immaturity of the intestinal immune system and allows the intestinal immunity to develop and refine more slowly than systemic immunity. The histological organisation and the balance of subtypes of lymphocytes and antigen-presenting cells in the lamina propria do not resemble those of the adult animal until this time, and mucosal responses to injected or mucosally-presented antigens lack intensity and discrimination.

Therefore, although there may be some benefit in terms of 'immune priming' associated with early vaccination, enhancing passive immunity by vaccinating sows is considered to be more effective than administering vaccine to sucking piglets (Ojha and Kostrzynska 2007). The apparently central importance of humoral immunity in resistance by mice to S. Typhimurium (McSorley and Jenkins 2000, Mittrücker and Kaufmann 2000) lends weight to this strategy. Colostral immunoglobulins correlate with the sow's serum immunoglobulin profile, whereas immunoglobulins in sows' milk, which are not absorbed systemically, reflect the patterns seen in maternal intestinal secretions (Bourne 1973, 1976). Therefore, administering a maternal vaccine of a type and by a route that ensures a good mucosal response may enhance ongoing intestinal defence against Salmonella throughout the preweaning period.

Oral, followed by parenteral, inoculation of pregnant sows with a killed preparation of an endemic $S$. Typhimurium strain on a nucleus breeder herd (Roesler and others 2006), was associated with the reduction of Salmonella excretion by sows, the elimination of excretion by piglets and near-complete protection for piglets from seroconversion post-weaning . Control piglets showed similar serovar-specific immunoglobulin levels until weaning, but these rose post-weaning, presumably in response to infection. It is interesting that the serological profiles initially would not distinguish piglets from vaccinated and non-vaccinated sows, but protection against post-weaning infections was clearly extended only to the vaccine group. Mechanisms postulated for this effect include: milk antibody acting locally in the pre-weaned piglet intestine, the colostral transfer of stimulated lymphocytes, and a reduction in challenge from excretion by the sows.

New immunological technologies which may prove equally or more effective in future include highly stable 'ghost cell' vaccines, providing membrane-associated antigen fractions only, and passive immunisation of piglets via egg yolk antibodies in feed (Ojha and Kostrzynska 2007). There are, however, a number of foreseeable limitations to vaccine programmes against Salmonella in the early life of pigs. These include different vaccines being needed to protect in different phases of development as challenge strains vary, and farm-specific vaccines, frequently against more than one strain, being needed for high efficacy against local strains. In addition there would be limited or no protection against novel strains brought in by water, feed or vectors, and serological freedom from infection would be difficult or impossible to demonstrate. There are also considerable practical and economic difficulties in ensuring that pigs on large commercial farms receive adequate doses of vaccine at suitable times. Limited field studies of vaccination in the UK (authors' unpublished data) have proved to be disappointing in terms of control of Salmonella spp., but may favourably influence the relative occurrence of certain serovars, e.g. $S$. Typhimurium, that are included in the vaccine.

\section{Competitive Exclusion}

Competitive exclusion (CE) trials have generally used undefined anaerobic caecal cultures, or subcultures, from healthy pigs. A caecal culture given at two weeks of age was ineffective against colonisation by a bolus of between $10^{4}$ and $10^{8} \mathrm{cfu} S$. Choleraesuis given one day later 
(Anderson and others 1998). A large intestinal culture given to younger piglets, at four and 24 hours of age, reduced pre-weaning transmission and post-weaning excretion of

$S$. Choleraesuis, both from seeder animals inoculated orally with the serovar and from incontacts (Genovese and others 2003). However, neither prevention of tissue colonisation nor elimination of Salmonella was achieved. A similar subtotal protective effect was seen following administration of a caecal culture at less than 12 hours of age plus at weaning (two weeks), against an oral bolus of $10^{6}$ to $10^{7} \mathrm{cfu} S$. Choleraesuis administered a day after weaning (Anderson and others 1999). Therefore, the limited reports to date suggest that CE needs to be commenced at a very young age to be beneficial, and this benefit is in the realm of reducing rather than preventing Salmonella infection of weaners.

\section{Feed and/or water treatments}

Most reports of trials involving treatment of feed and/or water involve animals in the later stages of fattening. Findings in any age group appear to be highly variable between studies, possibly reflecting variation in agents and concentrations used and in Salmonella challenge levels.

Providing weaners purchased from endemically-infected herds with feed supplemented with a high level $(2.8 \%)$ of lactic acid reduced the frequency of Salmonella-positive pen samples (Jørgensen and others 2001). However, feeding weaners at 18 days of age and above with organic or organic plus inorganic acid-supplemented feed had no effect on the presence of endemic Salmonella in faeces (Walsh and others 2007).

Fattening pigs exposed naturally and artificially to Salmonella in feed, and to $0.9 \%$ formic acid also in feed, showed a significant reduction in isolations of Salmonella from internal lymph nodes at slaughter, when compared with those on untreated feed (Vanderwal 1979). Four-week-old weaners exposed to $S$. Derby via seeder animals showed a lower prevalence or duration of excretion when feed was treated with organic acids $(0.9 \%$ formic acid / propionic acid blend) or $1.2 \%$ potassium diformate, respectively, than controls (Taube and others 2009). However, a field trial with in-feed organic acids from weaning onwards in the context of endemic Salmonella infection showed no benefit in terms of Salmonella excretion or serum ELISAs in the post-weaning and rearing period, or in slaughter meat juice ELISAs (O'Connor and others 2005).

Chlorate salts can effect suppression in vivo of enteric facultative anaerobes, including Salmonella, via a bacterial respiratory nitrate reductase, which converts chlorate to cytotoxic chlorite. Among pigs, significant reductions in large intestinal counts of both inoculated Salmonella and E. coli of the natural flora have been reported from weaners and finishers treated with chlorate preparations (Anderson and others 2004, 2006). Dietary nitrate was hypothesised to have an antimicrobial effect via the in vivo derived nitrite anion, but supplementing weaner feed with up to $150 \mathrm{mg} / \mathrm{kg}$ nitrate did not prove to be protective against colonisation of the foregut by a challenge $S$. Typhimurium strain (Modesto and others 2008).

The effects of feed form (pellet versus meal) on Salmonella prevalence have been discussed above. In addition, a strong protective effect of fermented liquid feed, including whey, upon Salmonella seroprevalence and excretion has been reported for finisher pigs (Lo Fo Wong and others 2004, Farzan and others 2006, Poljak and others 2008), an effect that appears to be dependent upon a sufficiently low pH in the feed (Dahl 2008). Systematic studies on the effects of such feeds on Salmonella in weanling pigs are lacking, but a protective effect would be expected at this age too if the observed benefits are attributable to the $\mathrm{pH}$ and organic acid content of the feed. The composition and quality of fermented diets 
may, however, be an issue in respect of weanling growth and post-weaning diarrhoea (Amezcua and others 2007).

Letellier and others (2000) added $0.02 \%$ formic acid to the drinking water of early-weaned piglets and challenged them with $S$. Typhimurium two weeks later. Reductions in Salmonella colonisation of mesenteric lymph nodes were not observed with this treatment.

\section{Early weaning, with or without transfer to clean sites}

Medicated early weaning (Alexander and others 1980) was originally trialled at around five days of age, with antibiotic treatment and using only the strongest piglets from a litter. Salmonella was not among the bacteria studied, and problems included mortality postweaning after withdrawal of the antibiotics. The effectiveness of the procedure varied according to the bacterial species examined. With an increased age at weaning (seven to 10 days) and no medication, except carbadox growth promoter, some bacterial pathogens were eliminated, others had the post-weaning infection burden reduced, and others were not controlled (Dritz and others 1996). Salmonella was again not examined.

Nietfeld and others $(1995,1998)$ subjected 56 piglets from a farm with endemic

$S$. Choleraesuis to segregated off-site early weaning at 10-16 days of age. None of the earlyweaned piglets excreted Salmonella and serological Salmonella titres declined and remained low. Control piglets weaned later and left on-farm had increasing titres to $S$. Choleraesuis by 40 days post-weaning and excreted a number of Salmonella serovars. Sows had been given a modified live $S$. Choleraesuis vaccine before farrowing, which may have contributed to the success of the procedure.

In another segregated early weaning trial (Fedorka-Cray and others 1997) approximately 400 piglets from two farms were weaned at two to three weeks to separate premises under strict biosecurity. The source farms had endemic salmonellas including serovars Typhimurium and Derby and did not vaccinate against Salmonella. Salmonella was not isolated from rectal, tonsil and nasal swabs from the litters, up to six weeks of age, of Salmonella-excreting sows in four of seven trials. There was no evidence of Salmonella in sows or piglets in two more trials.

Dahl and others (1997) used an approach of testing all stages from farrowing to finishing on three farms with endemic $S$. Typhimurium, and moving pigs from an uninfected stage to segregated, clean accommodation, rather than to accommodation where infection had been detected previously. On one farm, segregated weaning at 21 days to new accommodation from infected farrowing accommodation was practised. This movement and segregation was performed with pigs up to $30 \mathrm{~kg}$, depending on the stages that were infected on-farm. All such segregated groups proved to be negative for Salmonella when faeces and/or slaughter samples were tested, and were seronegative at slaughter. Some of the unsegregated control pigs excreted $S$. Typhimurium and/or were seropositive.

An early weaning trial was performed for piglets of Salmonella-excreting sows at 10 days of age, without off-site segregation. This reduced but did not eliminate Salmonella excretion 10 days later, compared with conventional weaning at 21 days (Patchanee and others 2005). Testing of piglets around weaning and diversion of Salmonella-positive individuals to separate premises was associated with elimination of $S$. Yoruba in an integrated breeding and rearing operation within a few months (Österberg and others 2001).

It therefore appears to be possible to eliminate Salmonella of persistent serovars from piglets by segregated weaning even from excreting sows, but success is far from guaranteed, even with the high levels of hygiene achievable in an experimental setup (Fedorka-Cray and others 1997). The requirements for clean weaning and excellent hygiene make successful Salmonella elimination by segregated weaning more difficult to achieve in the field (Dahl 
2008). Where a single serovar is endemic and restricted to certain production stages, the chances of success may be higher.

An important consideration is the availability of accommodation, from weaning onwards, that is free from Salmonella contamination. This can be a very challenging requirement in view of the limitations of many disinfectants in farm environments (McLaren and others), the poor efficacy of many cleaning and disinfection regimes (Mannion and others 2007, Wales and others 2009), the ubiquity of rodent vectors (Berends and others 1996) and the environmental robustness of Salmonella (Guan and Holley 2003).

It is not clear from the published trials, and from colostral immunity profiles, that weaning before three weeks of age is necessarily advantageous for the elimination of Salmonella. It may be that ensuring good colostral transfer of passive immunity by interventions around farrowing (such as balancing litter sizes, removing weak piglets and provision of adequate warmth and suitable surfaces to ensure piglet vigour and early suckling) and the vaccination of gilts and sows is more likely to ensure success. The rejection of poorly-developing piglets from weaning groups may also reduce the likelihood of Salmonella carryover. The protective effect of maternal passive immunity against a number of diseases is influenced by: parity, milking ability and stability of disease in the breeding herd (Amass 1998). Similarly, piglet factors include litter size, birth order, birth-weight and any cross-fostering. Careful monitoring of groups of sows, with selection of piglets from groups with no evidence of infection is likely to increase the chance of a successful outcome and to facilitate the development of new Salmonella-free groups of breeding pigs.

\section{Combined and other interventions}

In a SPF nucleus breeding herd with endemic $S$. Typhimurium DT104, the use of peracetic acid disinfection of farrowing and grower accommodation, plus washing the body surfaces of sows with the same agent, resulted in no detectable salmonellae in the farrowing units or on sows (Roesler and others 2005). Nonetheless, the infection of piglets from birth and into the grower phase by the same DT104 strain was not prevented by this measure, nor by the additional use of acidified feed plus treatment of sows and piglets with enrofloxacin from a week before farrowing until weaning.

Strategies that aim for a comprehensive and persistent pressure to reduce Salmonella challenge and excretion in an infected herd have ultimately met with success in eliminating the pathogen over a period of months in control programmes such as those employed in Sweden (Österberg and others 2001, 2006, Österberg 2010). These measures are characterised by severe restrictions on the movement and marketing of pigs from infected premises plus intensive efforts at segregation, depopulation, cleaning, disinfection and testing. It is evident that such sustained, thorough and multi-stage interventions can progressively reduce Salmonella infection cycles to extinction, and this approach provides an exemplar for the maintenance of low- or zero-Salmonella herd status. However for pig units, particularly large ones, with longstanding endemic Salmonella contamination and without a regulatory and financial imperative, such sustained intensive control measures have proved difficult to implement effectively due to cost and labour requirements (Wales and others 2009).

Increased fermentable fibre in piglet diet suppresses clinical manifestations of ST in orally inoculated piglets (Correa-Matos and others 2003), so may have potential for reducing susceptibility to infection in the early post-weaning period. The possible benefits of such an intervention need to be considered with other potential benefits and drawbacks such as reduced gastric ulceration and increased susceptibility to swine dysentery (Pluske and others 1996, Bilic and Bilkei 2003), although the balance of cost and benefit is likely to differ according to the age of pigs and the presence or otherwise of pathogens other than Salmonella 
(Jeaurond and others 2008). There is also always an additional productivity reduction cost associated with providing a less commercial diet, unless this can be offset by the reduced cost of home-milled feed.

Manipulating photoperiod has been shown to affect $S$. Typhimurium excretion in experimentally seeded groups in a short term study, whereby rectal swabs from pigs subjected to eight-hour days were less frequently Salmonella-positive than were those from pigs subjected to 16-hour days (Edrington and others 2007). In the European Union, legislation (Council Directive 91/630/EEC) prevents the restriction of photoperiod to less than eight hours a day.

\section{Testing}

To assist decision-making in, for example, segregated weaning systems, and to evaluate the effects of interventions, it is necessary to have reliable and practicable tests for the presence and burden of Salmonella. For the detection of Salmonella in groups of pigs, pooled faeces have proved to be a sensitive and economical sample (Arnold and Cook 2009, Wilkins and others 2009), provided that culture of the samples is performed using a sensitive method.

Serology, typically using a mixed anti-lipopolysaccharide ELISA, is a useful tool for monitoring herd infection ante- and post-mortem using serum and meat-drip samples. Roesler and others (2005) found that the temporal pattern of serological titres correlated well with excretion of $S$. Typhimurium in piglets and growers. However, serological responses are highly variable between individuals and appear to decline substantially one to two months post-infection in immunologically naïve animals (Nielsen and others 1995). In addition there will always be a delay of at least seven to 10 days between infection of an individual and the onset of a serological response. In view of this, the interpretation of serological data needs to take account of the cut-off values chosen to separate positive and negative results, and serology should be regarded as a tool for examining group, and not individual, status. In addition, the mix of capture antigens used in the test will affect which of the serogroupspecific responses are detected. Often, only moderate agreement is seen in comparative studies of different Salmonella ELISA tests (Poulin and others 2010). A study at slaughter showed that, whilst a commercial mixed-antigen ELISA with a $20 \%$ OD cut-off produced similar individual animal prevalence values to mesenteric lymph node culture, there was only modest correlation between the animals found positive by the two methods (Nollet and others 2005c). In addition, the ELISA was insensitive when interpreted at OD cut-off values above $10 \%$ for animals yielding some of the less common Salmonella serotypes from mesenteric lymph node culture. Nonetheless, serological monitoring using appropriate capture antigens can prove sensitive to infection in a group when faecal monitoring may miss low frequency excretion.

\section{Conclusions}

The carriage of Salmonella by piglets is readily demonstrated from farrowing accommodation onwards, although it is uncertain whether true infection (with colonisation of the intestinal tract and tissue invasion) occurs commonly under normal conditions in healthy pre-weaned pigs. The patterns of Salmonella infection in the weaner and grower stages can be highly variable, and most interventions, such as feed modification, competitive exclusion and vaccination of young or breeding stock, show variable effectiveness and do not tend to eliminate the problem. One approach that does have the potential to eliminate Salmonella from groups of weaners is segregated weaning to clean accommodation. However, even in 
experimental environments the technique has often failed to achieve this goal. To be consistently successful in the field, segregated weaning probably requires attention to numerous identified factors and reliable testing protocols in addition to the provision of suitable accommodation and excellent standards of hygiene. However, early weaning (before three weeks of age) may not significantly improve the chance of success, and in any event such a procedure is not permitted under current EU legislation (Council Directive 91/630/EEC). The technique may benefit from assistance by other interventions such as maternal Salmonella vaccination. Systems that aim to minimise the frequency and degree of animal movements, social disruption and bullying could contribute to reducing Salmonella infection levels, and potentially could increase the success rate at preventing Salmonella carryover at weaning.

Experience from the Scandinavian Peninsula, where Salmonella is often associated with feed contamination and infections are addressed by intensive (and expensive) control and monitoring measures, indicates that herd infections typically take some months to clear. The consistent provision of Salmonella-free weaners should be seen as a considerable asset in this context, but the temptation to regard it as a one-step solution should be resisted. In the commonly-encountered endemic situation, Salmonella challenge will initially exist via varied routes and at many stages of production.

Despite some uncertainty about ultimate success rates, the goal of reliably achieving Salmonella-free weaners, or at least freedom from major zoonotic serovars such as $S$. Typhimurium, would be of major potential benefit to the pig industry in the existing and anticipated regulatory and marketing environment. 


\section{References}

ALEXANDER, T. J., THORNTON, K., BOON, G., LYSONS, R. J. \& GUSH, A. F. (1980) Medicated early weaning to obtain pigs free from pathogens endemic in the herd of origin. Veterinary Record 106, 114-119

AMAECHI, N. \& EZERONYE, O. U. (2006) Piggery environment as a source of Salmonella contamination for swine. Journal of Animal and Veterinary Advances 5, 102-107

AMASS, S. (1998) The effect of weaning age on pathogen removal. Compendium on Continuing Education for the Practicing Veterinarian 20, S196-S203

AMEZCUA, M. D., FRIENDSHIP, R., DEWEY, C., WEESE, J. S., DE LANGE, C. \& REID, G. (2007) Effects on growth performance, feed efficiency, and health of weanling pigs fed fermented liquid whey inoculated with lactic acid bacteria that inhibit Escherichia coli in vitro. Journal of Swine Health and Production 15, 320-329

ANDERSON, R. C., HUME, M. E., GENOVESE, K. J., CALLAWAY, T. R., JUNG, Y. S., EDRINGTON, T. S., POOLE, T. L., HARVEY, R. B., BISCHOFF, K. M. \& NISBET, D. J. (2004) Effect of drinking-water administration of experimental chlorate ion preparations on Salmonella enterica serovar Typhimurium colonization in weaned and finished pigs. Veterinary Research Communications 28, 179-189

ANDERSON, R. C., JUNG, Y. S., GENOVESE, K. J., MCREYNOLDS, J. L., CALLAWAY, T. R., EDRINGTON, T. S., HARVEY, R. B. \& NISBET, D. J. (2006) Low level nitrate or nitroethane preconditioning enhances the bactericidal effect of suboptimal experimental chlorate treatment against Escherichia coli and Salmonella typhimurium but not Campylobacter in swine. Foodborne Pathogens and Disease 3, 461-465

ANDERSON, R. C., NISBET, D. J., BUCKLEY, S. A., GENOVESE, K. J., HARVEY, R. B., DELOACH, J. R., KEITH, N. K. \& STANKER, L. H. (1998) Experimental and natural infection of early weaned pigs with Salmonella choleraesuis. Research in Veterinary Science 64, 261-262

ANDERSON, R. C., STANKER, L. H., YOUNG, C. R., BUCKLEY, S. A., GENOVESE, K. J., HARVEY, R. B., DELOACH, J. R., KEITH, N. K. \& NISBET, D. J. (1999) Effect of competitive exclusion treatment on colonization of early-weaned pigs by Salmonella serovar Choleraesuis. Swine Health and Production 7, 155-160

ANON (2006a) Opinion of the Scientific Panel on Biological Hazards on "Risk assessment and mitigation options of Salmonella in pig production". EFSA Journal, 341, 1-131.

http://www.efsa.europa.eu/EFSA/efsa_locale-1178620753812_1178620776028.htm Accessed 16th September 2008

ANON (2006b) Salmonella in livestock production in GB 2005. Veterinary Laboratories Agency. http://www.defra.gov.uk/vla/reports/rep_salm_rep05.htm Accessed 27th September 2010

ARNOLD, M. E. \& COOK, A. J. C. (2009) Estimation of sample sizes for pooled faecal sampling for detection of Salmonella in pigs. Epidemiology and Infection 137, 1734-1741 
BARBER, D. A., BAHNSON, P. B., ISAACSON, R., JONES, C. J. \& WEIGEL, R. M. (2002) Distribution of Salmonella in swine production ecosystems. Journal of Food Protection 65, 1861-1868

BELGEIL, P. A., CHAUVIN, C., PROUX, K., ROSE, N., QUEGUINER, S., EVENO, E., HOUDAYER, C., ROSE, V., FRAVALO, P. \& MADEC, F. (2003) Longitudinal serological responses to Salmonella enterica of growing pigs in a subclinically infected herd. Preventive Veterinary Medicine 60, 207-226

BERENDS, B. R., URLINGS, H. A. P., SNIJDERS, J. M. A. \& KNAPEN, F. V. (1996) Identification and quantification of risk factors in animal management and transport regarding Salmonella spp. in pigs. International Journal of Food Microbiology 30, 37-53

BILIC, B. \& BILKEI, G. (2003) Effect of highly fermentable dietary fiber on pig performance in a large unit, infected with endemic swine dysentery. Acta VeterinariaBeograd 53, 229-238

BOURNE, F. J. (1973) The immunoglobulin system of the suckling pig. Proceedings of the Nutrition Society 32, 205-215

BOURNE, F. J. (1976) Humoral immunity in the pig. Veterinary Record 98, 499-501

BOYEN, F., HAESEBROUCK, F., MAES, D., VAN IMMERSEEL, F., DUCATELLE, R. \& PASMANS, F. (2008) Non-typhoidal Salmonella infections in pigs: A closer look at epidemiology, pathogenesis and control. Veterinary Microbiology 130, 1-19

CALLAWAY, T. R., MORROW, J. L., EDRINGTON, T. S., GENOVESE, K. J., DOWD, S., CARROLL, J., DAILEY, J. W., HARVEY, R. B., POOLE, T. L., ANDERSON, R. C. \& NISBET, D. J. (2006) Social stress increases fecal shedding of Salmonella Typhimurium by early weaned piglets. Current Issues in Intestinal Microbiology 7, 65-71

CORREA-MATOS, N. J., DONOVAN, S. M., ISAACSON, R. E., GASKINS, H. R., WHITE, B. A. \& TAPPENDEN, K. A. (2003) Fermentable fiber reduces recovery time and improves intestinal function in piglets following Salmonella typhimurium infection. Journal of Nutrition 133, 1845-1852

DAHL, J. (2008) Feed related interventions in pig herds with a high salmonella seroprevalence - the Danish experience. The Pig Journal 61, 6-11

DAHL, J., WINGSTRAND, A., NIELSEN, B. \& BAGGESEN, D. L. (1997) Elimination of Salmonella typhimurium infection by the strategic movement of pigs. Veterinary Record 140 , 679-681

DAVIES, P. R., FUNK, J. A. \& MORROW, W. E. M. (2000) Fecal shedding of Salmonella by gilts before and after introduction to a swine breeding farm. Swine Health and Production $\mathbf{8}, 25-29$

DAVIES, R. H., DALZIEL, R., GIBBENS, J. C., WILESMITH, J. W., RYAN, J. M. B., EVANS, S. J., BYRNE, C., PAIBA, G. A., PASCOE, S. J. S. \& TEALE, C. J. (2004) National survey for Salmonella in pigs, cattle and sheep at slaughter in Great Britain (19992000). Journal of Applied Microbiology 96, 750-760 
DRITZ, S. S., CHANGAPPA, M. M., NELSSEN, J. L., TOKACH, M. D., GOODBAND, R. D., NIETFELD, J. C. \& STAATS, J. J. (1996) Growth and microbial flora of nonmedicated, segregated, early weaned pigs from a commercial swine operation. Journal of the American Veterinary Medical Association 208, 711-

EDRINGTON, T., CALLAWAY, T., GENOVESE, K. J., ANDERSON, R. \& NISBET, D. (2007) Influence of light exposure on horizontal transmission of Salmonella typhimurium in weaned pigs. Proceedings of 7th International Symposium on the Epidemiology and Control of Foodborne Pathogens in Pork (SAFEPORK 2007). Verona, Italy, 9-11 May, 2007. pp 441444

EFSA (2008) Report of the task force on zoonoses data collection on the analysis of the baseline survey on the prevalence of Salmonella in slaughter pigs, Part A: Salmonella prevalence estimates. EFSA Journal, 135, 1-111.

http://www.efsa.europa.eu/EFSA/efsa_locale-1178620753812_1178713190037.htm Accessed Sept 16th 2008

EUROPEAN FOOD SAFETY AUTHORITY (2006) The Community summary report on trends and sources of zoonoses, zoonotic agents, antimicrobial resistance and foodborne outbreaks in the European Union in 2005. The EFSA Journal 94, 65-73

FARZAN, A., FRIENDSHIP, R. M., DEWEY, C. E., WARRINER, K., POPPE, C. \& KLOTINS, K. (2006) Prevalence of Salmonella spp. on Canadian pig farms using liquid or dry-feeding. Preventive Veterinary Medicine 73, 241-254

FEDORKA-CRAY, P. J., HARRIS, D. L. \& WHIPP, S. C. (1997) Using isolated weaning to raise salmonella-free swine. Veterinary Medicine 92, 375-382

FEDORKA-CRAY, P. J., WHIPP, S. C., ISAACSON, R. E., NORD, N. \& LAGER, K. (1994) Transmission of Salmonella typhimurium to swine. Veterinary Microbiology 41, 333344

FRIENDSHIP, R. M., MOUNCHILI, A., MCEWEN, S. \& RAJIĆ, A. (2009) Critical review of on-farm intervention strategies against Salmonella. British Pig Executive (BPEX). http://www.bpex.org/Article.aspx?ID=298614 Accessed 27th September 2010

FUNK, J. A., DAVIES, P. R. \& NICHOLS, M. A. (2001) Longitudinal study of Salmonella enterica in growing pigs reared in multiple-site swine production systems. Veterinary Microbiology 83, 45-60

GENOVESE, K. J., ANDERSON, R. C., HARVEY, R. B., CALLAWAY, T. R., POOLE, T. L., EDRINGTON, T. S., FEDORKA-CRAY, P. J. \& NISBET, D. J. (2003) Competitive exclusion of Salmonella from the gut of neonatal and weaned pigs. Journal of Food Protection 66, 1353-1359

GRAY, J. T., FEDORKA-CRAY, P. J., STABEL, T. J. \& KRAMER, T. T. (1996) Natural transmission of Salmonella choleraesuis in swine. Applied and Environmental Microbiology 62, 141-146

GUAN, T. Y. \& HOLLEY, R. A. (2003) Pathogen survival in swine manure environments and transmission of human enteric illness - a review. J Environ Qual 32, 383-392 
HACKING, W. C., MITCHELL, W. R. \& CARLSON, H. C. (1978) Salmonella investigation in an Ontario feed mill. Canadian Journal of Comparative Medicine 42, 400-406

HÄGGBLOM, P. (2009) The feed borne outbreak of Salmonella Tennessee in Finland in the spring of 2009. National Veterinary Institute Sweden (SVA). Uppsala, Sweden, p. 20. http://www.mmm.fi/attachments/mmm/tiedotteet $/ 5 \mathrm{mlkunEwY} /$ The feed borne outbreak_of Salmonella_Tennessee_in_Finland_in_the_spring_of_2009.pdf Accessed Sept 27th 2010

JEAUROND, E. A., RADEMACHER, M., PLUSKE, J. R., ZHU, C. H. \& DE LANGE, C. F. M. (2008) Impact of feeding fermentable proteins and carbohydrates on growth performance, gut health and gastrointestinal function of newly weaned pigs. Canadian Journal of Animal Science 88, 271-281

JONES, F. T. \& RICHARDSON, K. E. (2004) Salmonella in commercially manufactured feeds. Poultry Science 83, 384-391

JONES, P. H., ROE, J. M. \& MILLER, B. G. (2001) Effects of stressors on immune parameters and on the faecal shedding of enterotoxigenic Escherichia coli in piglets following experimental inoculation. Research in Veterinary Science 70, 9-17

JØRGENSEN, L., KJÆRSGAARD, H. D., WACHMANN, H., JENSEN, B. B. \& KNUDSEN, K. E. B. (2001) Salmonella prevalence and productivity in weaners. Proceedings of 4th International Symposium on Epidemiology and Control of Salmonella and other Foodborne Pathogens in Pork (Salinpork 2001). Leipzig, Germany, 2-5 September, 2001. pp 109-111

KJÆRSGAARD, H. D., JØRGENSEN, L., WACHMANN, H. \& DAHL, J. (2001) Effect on Salmonella prevalence by feeding sows meal or pelleted feed. Proceedings of 4th International Symposium on Epidemiology and Control of Salmonella and other Foodborne Pathogens in Pork (Salinpork 2001). Leipzig, Germany, 2-5 September, 2001. pp 115-117

KORSAK, N., JACOB, B., GROVEN, B., ETIENNE, G., CHINA, B., GHAFIR, Y. \& DAUBE, G. (2003) Salmonella contamination of pigs and pork in an integrated pig production system. Journal of Food Protection 66, 1126-1133

KRANKER, S., ALBAN, L. \& BOES, J. (2003a) Longitudinal study of Salmonella enterica serovar Typhimurium infection in three Danish farrow-to-finish swineherds. Proceedings of 5th International Symposium on the Epidemiology and Control of Foodborne Pathogens in Pork (SAFEPORK 2003). Heraklion, Crete, Greece, 1-4 October, 2003a. pp 241-242

KRANKER, S., ALBAN, L., BOES, J. \& DAHL, J. (2003b) Longitudinal study of Salmonella enterica serotype Typhimurium infection in three Danish farrow-to-finish swine herds. Journal of Clinical Microbiology 41, 2282-2288

KRANKER, S., DAHL, J. \& WINGSTRAND, A. (2001) Bacteriological and serological examination and risk factor analysis of Salmonella occurrence in sow herds, including risk factors for high Salmonella seroprevalence in receiver finishing herds. Berliner und Münchener Tierärztliche Wochenschrift 114, 350-352

LARSEN, S. T., MCKEAN, J. D., HURD, H. S., ROSTAGNO, M. H., GRIFFITH, R. W. \& WESLEY, I. V. (2003) Impact of commercial preharvest transportation and holding on the prevalence of Salmonella enterica in cull sows. Journal of Food Protection 66, 1134-1138 
LETELLIER, A., MESSIER, S., LESSARD, L. \& QUESSY, S. (2000) Assessment of various treatments to reduce carriage of Salmonella in swine. Canadian Journal of Veterinary Research 64, 27-31

LETELLIER, A., MESSIER, S., PARE, J., MENARD, J. \& QUESSY, S. (1999) Distribution of Salmonella in swine herds in Quebec. Veterinary Microbiology 67, 299-306

LINDBERG, A. A. \& ROBERTSSON, J. A. (1983) Salmonella typhimurium infection in calves: cell-mediated and humoral immune reactions before and after challenge with live virulent bacteria in calves given live or inactivated vaccines. Infection and Immunity 41, 751757

LO FO WONG, D. M. A., DAHL, J., STEGE, H., VAN DER WOLF, P. J., LEONTIDES, L., VON ALTROCK, A. \& THORBERG, B. M. (2004) Herd-level risk factors for subclinical Salmonella infection in European finishing-pig herds. Preventive Veterinary Medicine 62 , 253-266

LUMSDEN, J. S. \& WILKIE, B. N. (1992) Immune response of pigs to parenteral vaccination with an aromatic-dependent mutant of Salmonella typhimurium. Canadian Journal of Veterinary Research 56, 296-302

LUMSDEN, J. S., WILKIE, B. N. \& CLARKE, R. C. (1991) Resistance to fecal shedding of salmonellae in pigs and chickens vaccinated with an aromatic-dependent mutant of Salmonella typhimurium. American Journal of Veterinary Research 52, 1784-1787

MANNION, C., LYNCH, P. B., EGAN, J. \& LEONARD, F. C. (2007) Efficacy of cleaning and disinfection on pig farms in Ireland. Veterinary Record 161, 371-375

MCLAREN, I., WALES, A., BRESLIN, M. \& DAVIES, R. (2011) Evaluation of commonlyused farm disinfectants in wet and dry models of Salmonella farm contamination. Avian Pathology In press

MCSORLEY, S. J. \& JENKINS, M. K. (2000) Antibody is required for protection against virulent but not attenuated Salmonella enterica serovar Typhimurium. Infection and Immunity 68, 3344-3348

MERIALDI, G., BARIGAZZI, G., BONILAURI, P., TITTARELLI, C., BONCI, M., D'INCAU, M. \& DOTTORI, M. (2008) Longitudinal study of Salmonella infection in Italian farrow-to-finish swine herds. Zoonoses and Public Health 55, 222-226

MITTRÜCKER, H. W. \& KAUFMANN, S. H. (2000) Immune response to infection with Salmonella typhimurium in mice. Journal of Leukocyte Biology 67, 457-463

MODESTO, M., D'AIMMO, M. R., STEFANINI, I., MAZZONI, M., BOSI, P. \& BIAVATI, B. (2008) Antimicrobial effect of dietary nitrate in weaning piglets challenged or not with Salmonella enterica serovar Typhimurium. In Proceedings of the Second Scientific Conference of the International Society of Organic Agriculture Research (ISOFAR). Modena, Italy. pp 146-149

NEWELL, K. W., MCCLARIN, R., MURDOCK, C. R., MACDONALD, W. N. \& HUTCHINSON, H. L. (1959) Salmonellosis in Northern Ireland, with special reference to pigs and salmonella contaminated pig meal. Journal of Hygiene 57, 92-105 
NIELSEN, B., BAGGESEN, D., BAGER, F., HAUGEGAARD, J. \& LIND, P. (1995) The serological response to Salmonella serovars typhimurium and infantis in experimentally infected pigs. The time course followed with an indirect anti-LPS ELISA and bacteriological examinations. Veterinary Microbiology 47, 205-218

NIETFELD, J. C., FEDER, I., KRAMER, T. T., SCHONEWEIS, D. \& CHENGAPPA, M. M. (1998) Preventing Salmonella infection in pigs with offsite weaning. Swine Health and Production 6, 27-32

NIETFELD, J. C., FEDER, I., SCHONEWEIS, D. \& KELLY, B. (1995) Evaluation of segregated early weaning to control salmonellosis and proliferative enteritis. Kansas State University Swine Day 1995, Report of Progress 746. Kansas State University, pp. 14-17. http://www.asi.k-state.edu/DesktopDefault.aspx?tabid=245 Accessed 27th September 2010

NOLLET, N., HOUF, K., DEWULF, J., DE KRUIF, A., DE ZUTTER, L. \& MAES, D. (2003a) Dynamics of subclinical Salmonella infections in farrow-to-finish pig herds. Proceedings of 5th International Symposium on the Epidemiology and Control of Foodborne Pathogens in Pork (SAFEPORK 2003). Heraklion, Crete, Greece, 1-4 October, 2003a. pp 5053

NOLLET, N., HOUF, K., DEWULF, J., DE KRUIF, A., DE ZUTTER, L. \& MAES, D. (2003b) Transmission of Salmonella from sows to piglets: a longitudinal study. Proceedings of 5th International Symposium on the Epidemiology and Control of Foodborne Pathogens in Pork (SAFEPORK 2003). Heraklion, Crete, Greece, 1-4 October, 2003b. pp 46-49

NOLLET, N., HOUF, K., DEWULF, J., DE KRUIF, A., DE ZUTTER, L. \& MAES, D. (2005a) Salmonella in sows: a longitudinal study in farrow-to-finish pig herds. Veterinary Research 36, 645-656

NOLLET, N., HOUF, K., DEWULF, J., DUCHATEAU, L., DE ZUTTER, L., DE KRUIF, A. \& MAES, D. (2005b) Distribution of Salmonella strains in farrow-to-finish pig herds: a longitudinal study. Journal of Food Protection 68, 2012-2021

NOLLET, N., MAES, D., DUCHATEAU, L., HAUTEKIET, V., HOUF, K., VAN HOOF, J., DE ZUTTER, L., DE KRUIF, A. \& GEERS, R. (2005c) Discrepancies between the isolation of Salmonella from mesenteric lymph nodes and the results of serological screening in slaughter pigs. Veterinary Research 36, 545-555

O'CONNOR, J. L., SNOW, L. C. \& COOK, A. J. (2005) A trial investigating the effect of organic acids in weaner pigs' diets on Salmonella prevalence in finisher pigs. Research in Veterinary Science 78, 25

OJHA, S. \& KOSTRZYNSKA, M. (2007) Approaches for reducing Salmonella in pork production. Journal of Food Protection 70, 2676-2694

OLIVEIRA, C. J. B., CARVALHO, L. F. O. S. \& GARCIA, T. B. (2006) Experimental airborne transmission of Salmonella Agona and Salmonella Typhimurium in weaned pigs. Epidemiology and Infection 134, 199-209

OLIVEIRA, C. J. B., GARCIA, T. B., CARVALHO, L. \& GIVISIEZ, P. E. N. (2007) Noseto-nose transmission of Salmonella Typhimurium between weaned pigs. Veterinary

Microbiology 125, 355-361 
ÖSTERBERG, J. (2010) Salmonella in pigs: infection dynamics of different serotypes. Ph.D Thesis, Faculty of Veterinary Medicine and Animal Sciences, Swedish University of Agricultural Sciences. Uppsala. 73 pp.

ÖSTERBERG, J., EKWALL, S. J., NILSSON, I., STAMPE, M., ENGVALL, A. \& WALLGREN, P. (2001) Eradication of Salmonella Yoruba in an integrated pig herd. Berliner Und Munchener Tierarztliche Wochenschrift 114, 331-334

ÖSTERBERG, J., VÅGSHOLM, I., BOQVIST, S. \& STERNBERG LEWERIN, S. (2006) Feed-borne outbreak of Salmonella Cubana in Swedish pig farms: risk factors and factors affecting the restriction period in infected farms. Acta Veterinaria Scandinavica 47, 13-22

PATCHANEE, P., BAHNSON, P. B. \& CRENSHAW, T. D. (2005) Clorate and disinfectant modify Salmonella enterica shedding in weaned pigs. Proceedings of 6th International Symposium on the Epidemiology and Control of Foodborne Pathogens in Pork (SAFEPORK 2005). Rohnert Park, California, USA, 6-9 September, 2005. pp 139-141

PAULIN, S. M., JAGANNATHAN, A., CAMPBELL, J., WALLIS, T. S. \& STEVENS, M. P. (2007) Net replication of Salmonella enterica serovars Typhimurium and Choleraesuis in porcine intestinal mucosa and nodes is associated with their differential virulence. Infection and Immunity 75, 3950-3960

PLUSKE, J. R., SIBA, P. M., PETHICK, D. W., DURMIC, Z., MULLAN, B. P. \& HAMPSON, D. J. (1996) The incidence of swine dysentery in pigs can be reduced by feeding diets that limit the amount of fermentable substrate entering the large intestine. Journal of Nutrition 126, 2920-2933

POLJAK, Z., DEWEY, C. E., FRIENDSHIP, R. M., MARTIN, S. W. \& CHRISTENSEN, J. (2008) Multilevel analysis of risk factors for Salmonella shedding in Ontario finishing pigs. Epidemiology and Infection 136, 1388-1400

POULIN, M. C., DONADEU, M., MACKAY, E. K., PENMAN, K. L. \& THOMSON, J. R. (2010) Comparative study of three porcine Salmonella ELISAs. Veterinary Record 166, 500501

PROUX, K., HOUDAYER, C., HUMBERT, F., CARIOLET, R., ROSE, V., EVENO, E. \& MADEC, F. (2000) Development of a complete ELISA using Salmonella lipopolysaccharides of various serogroups allowing to detect all infected pigs. Veterinary Research 31, 481-490

REED, W. M., OLANDER, H. J. \& THACKER, H. L. (1985) Studies on the pathogenesis of Salmonella heidelberg infection in weanling pigs. American Journal of Veterinary Research 46, 2300-2310

REED, W. M., OLANDER, H. J. \& THACKER, H. L. (1986) Studies on the pathogenesis of Salmonella typhimurium and Salmonella choleraesuis var kunzendorf infection in weanling pigs. American Journal of Veterinary Research 47, 75-83

ROBERTSSON, J. A., LINDBERG, A. A., HOISETH, S. \& STOCKER, B. A. (1983) Salmonella typhimurium infection in calves: protection and survival of virulent challenge bacteria after immunization with live or inactivated vaccines. Infection and Immunity 41, 742750 
ROESLER, U., HELLER, P., WALDMANN, K. H., TRUYEN, U. \& HENSEL, A. (2006) Immunization of sows in an integrated pig-breeding herd using a homologous inactivated Salmonella vaccine decreases the prevalence of Salmonella Typhimurium infection in the offspring. Journal of Veterinary Medicine Series B 53, 224-228

ROESLER, U., MARG, H., SCHRÖDER, I., MAUER, S., ARNOLD, T., LEHMANN, J., TRUYEN, U. \& HENSEL, A. (2004) Oral vaccination of pigs with an invasive gyrA-cpxArpoB Salmonella Typhimurium mutant. Vaccine 23, 595-603

ROESLER, U., VON ALTROCK, A., HELLER, P., BREMERICH, S., ARNOLD, T., LEHMANN, J., WALDMANN, K. H., TRUYEN, U. \& HENSEL, A. (2005) Effects of fluoroquinolone treatment acidified feed, and improved hygiene measures on the occurrence of Salmonella Typhimurium DT104 in an integrated pig breeding herd. Journal of Veterinary Medicine Series B 52, 69-74

SHAPCOTT, R. C. (1985) Practical aspects of Salmonella control: progress report on a programme in a large broiler integration. In Proceedings of the International Symposium on Salmonella, New Orleans, 19-20 July 1984. Ed G. H. Snoeyenbos. Kennet Square, Pennsylvania, USA, American Association of Avian Pathologists. pp 109-114

SOUMPASIS, I. \& BUTLER, F. (2009) Development and application of a stochastic epidemic model for the transmission of Salmonella Typhimurium at the farm level of the pork production chain. Risk Analysis 29, 1521-1533

STOKES, C. R., BAILEY, M., HAVERSON, K., HARRIS, C., JONES, P., INMAN, C., PIE, S., OSWALD, I. P., WILLIAMS, B. A., AKKERMANS, A. D. L., SOWA, E., ROTHKOTTER, H. J. \& MILLER, B. G. (2004) Postnatal development of intestinal immune system in piglets: implications for the process of weaning. Animal Research 53, 325-334

TAUBE, V. A., NEU, M. E., HASSAN, Y., VERSPOHL, J., BEYERBACH, M. \& KAMPHUES, J. (2009) Effects of dietary additives (potassium diformate/organic acids) as well as influences of grinding intensity (coarse/fine) of diets for weaned piglets experimentally infected with Salmonella Derby or Escherichia coli. Journal of Animal Physiology and Animal Nutrition 93, 350-358

TAYLOR, D. (1989) Salmonellosis. In Pig diseases. 5th edn. Cambridge, UK, Burlington Press (Cambridge) Ltd. pp 100-104

TUNKL, B., PETRICEVIC, S., KARLOVIC, M., RUNIC, J. \& BUNDALO, M. (1978) Immunoprophylaxis of salmonellosis in piglets using inactivated vaccine in oil. Praxis Veterinaria 26, 9-15

VANDERWAL, P. (1979) Salmonella control of feedstuffs by pelleting or acid treatment. World's Poultry Science Journal 35, 70-78

VEGA-LÓPEZ, M. A., BAILEY, M., TELEMO, E. \& STOKES, C. R. (1995) Effect of early weaning on the development of immune cells in the pig small intestine. Veterinary Immunology and Immunopathology 44, 319-327

VELDMAN, A., VAHL, H. A., BORGGREVE, G. J. \& FULLER, D. C. (1995) A survey of the incidence of Salmonella species and Enterobacteriaceae in poultry feeds and feed components. Veterinary Record 136, 169-172 
WALES, A. D., MCLAREN, I. M., BEDFORD, S., CARRIQUE-MAS, J. J., COOK, A. J. C. \& DAVIES, R. H. (2009) Longitudinal survey of the occurrence of Salmonella in pigs and the environment of nucleus breeder and multiplier pig herds in England. Veterinary Record 165, 648-657

WALSH, M. C., SHOLLY, D. M., HINSON, R. B., TRAPP, S. A., SUTTON, A. L., RADCLIFFE, J. S., SMITH, J. W. \& RICHERT, B. T. (2007) Effects of acid LAC and KemGest acid blends on growth performance and microbial shedding in weanling pigs. Journal of Animal Science 85, 459-467

WILKINS, W., RAJIĆ, A., WALDNER, C., MCFALL, M., CHOW, E., MUCKLE, A. \& ROSENGREN, L. (2009) Distribution of Salmonella serovars in various pig production categories and risk factors for shedding in ten farrow-to-finish swine farms in western Canada. Proceedings of 8th International Symposium on the Epidemiology and Control of Foodborne Pathogens in Pork (SAFEPORK 2009). Québec City, Canada, 30 September - 2 October, 2009. pp 71-74

WILKINS, W., RAJIĆ, A., WALDNER, C., MCFALL, M., CHOW, E., MUCKLE, A. \& ROSENGREN, L. (2010) Distribution of Salmonella serovars in breeding, nursery, and growto-finish pigs, and risk factors for shedding in ten farrow-to-finish swine farms in Alberta and Saskatchewan. Canadian Journal of Veterinary Research 74, 81-90

WILLIAMS, D. R., HUNTER, D., BINDER, J. \& HOUGH, E. (1981) Observations on the occurrence of Salmonella cholerae-suis and other salmonellas in two herds of feeder pigs. Journal of Hygiene 86, 369-377

WOOD, R. L., POSPISCHIL, A. \& ROSE, R. (1989) Distribution of persistent Salmonella typhimurium infection in internal organs of swine. American Journal of Veterinary Research 50, $1015-1021$

WOOD, R. L. \& ROSE, R. (1992) Populations of Salmonella typhimurium in internal organs of experimentally infected carrier swine. American Journal of Veterinary Research 53, 653658

WOOD, R. L., ROSE, R., COE, N. E. \& FERRIS, K. E. (1991) Experimental establishment of persistent infection in swine with a zoonotic strain of Salmonella newport. American Journal of Veterinary Research 52, 813-819

WRAY, C. (2001) Review of research into Salmonella infections in pigs. UK Meat and Livestock Commission. MLC. http://v2.mlc.org.uk/downloads/pdfs/Salmonella_review.pdf Accessed 27th September 2010 